\title{
Effect of Global Postural Re- Education Method on Pulmonary Function And Chest Excursion in Moderate Chronic Obstructive Pulmonary Disease Subjects
}

\author{
T. Poovishnu devi ${ }^{1} *$ K.Divya sunder kummari ${ }^{2}$ Anitha kumari abbina ${ }^{3}$ \\ ${ }^{1}$ Associate Professor, Faculty Of Physiotherapy, Krishna Institute Of Medical Sciences Deemed University, \\ Karad ,Satara District, Maharastra. Pin Code -415110 \\ ${ }^{2}$ Post Graduate Student, Swatantra Institute Of Physiotherapy And Rehabilitation, Rajahmundhry, East \\ Godavari District, Andhra Pradesh. Pin Code -533105 \\ ${ }^{3}$ Principal, GSL College Of Physiotherapy, Rajahmundhry, East Godavari District, Andhra Pradesh. Pin Code
}

\begin{abstract}
:
Background: Chronic obstructive pulmonary disease (COPD) is characterized by airflow limitation, pulmonary hyperinflation with reduced muscle efficiency resulting in muscle shortening and reduced chest expansion . Stretching increases muscle length and reduce dyspnea. Global postural re-education (GPR) is used to stretch static muscles, increase flexibility and strength. The aim of the study is to find the effects of global postural re- education on pulmonary function and chest excursion in moderate COPD subjects.

Methods: 40 subjects between 40-50 years were selected by simple random sampling based on inclusion criteria. Baseline values of FEVI/FVC for pulmonary function and chest excursion were assessed. The treatment duration is 30 minutes for 2 days per week for 2 months. 20 patients received GPR with conventional physiotherapy and 20 patients received conventional physiotherapy. After 24 sessions, post test was taken Statistical analysis was done using paired t test and unpaired t test for within and between groups

Results: In control group pre- post analysis of FEVI/FVC is $p<0.0001$ and chest excursion is $p<0.0110$ and $p<0.0102$ is statistically not significant. In experimental group the pre-post analysis of FEVI/FVC is $p<0.0001$ and chest excursion is $p<0.0001$ and $p<0.0001$ is statistically significant. Analysis of effectiveness of experimental and control group, post test FEVI/FVC is $p<0.0001$ and chest excursion is $p<0.0001$ and $p<$ 0.0001 is extremely statistically significant.

Conclusion: Thus the above study concludes that GPR had significant improvement statistically on FEVI/FVC and chest excursion in moderate COPD patients. The study accepts alternate hypothesis.
\end{abstract}

Keywords : COPD,GPR, FEVI/FVC, Chest excursion.

\section{Introduction}

Chronic obstructive pulmonary disease (COPD) is characterized by airflow limitation which is usually progressive and associated with abnormal inflammatory response of the lung to noxious particles or gases (GOLD 2006) ${ }^{1}$. World Health Organization (WHO) estimated that 65 million people have moderate to severe $\mathrm{COPD}^{2}$.It is a major cause of morbidity and mortality throughout the world ${ }^{3,} .{ }^{4}$. It is known that almost $90 \%$ of COPD death occur in Low and Middle-income countries. ${ }^{5}$ WHO estimated that by 2030 COPD will be third leading cause of worldwide. ${ }^{6}$

Loss of skeletal muscle mass in COPD leads to muscle weakness. ${ }^{7}$ which impairs respiratory muscle function resulting in pulmonary hyperinflation, Barrel chest and geometry of chest wall is altered with hyperinflation leading to chronic reduction of the opposition zone of the diaphragm ${ }^{9.10}$.Hyperinflation change the diaphragm fiber arrangement and length which is an important determinant of force generating capacity ${ }^{8}$. Pulmonary hyperinflation can shorten diaphragm fiber sarcomere displacing it from its optimal length precipitating a decrease in the mechanical efficiency of the muscle ${ }^{12}$.

Due to inactivity, modifications of contractile proteins and metabolism of mitochondria, resulting in atrophy, weakness, and increased deposition of connective tissue leading to muscle shortening and limitation ,resulting in increase in lung volume at rest, chest featuring large diameter, there by restricting the mobility of ribcage $^{11}$. The length-associated changes can be induced by immobilization, muscle imbalance, postural mal alignment or combination of these ${ }^{13,14}$.

Shoulder and thoracic muscle stretching allows the muscle to recover its length necessary to maintain correct postural alignment,joint stability, especially ensuring the integrity and muscle function ${ }^{38}$. Even then, muscle fibers are incapable of lengthening, which requires an external force applied to the muscle ${ }^{23}$.

Static method is widely used to increase flexibility and achieve relaxation. During static stretching, the tension created in the muscle groups is of low intensity, allowing the patient to remain comfortable while 
achieving efficacy in the treatment. ${ }^{16,17}$ The method of global postural re-education (GPR) based on postural muscle chains presents special concern with lengthening (stretching) of respiratory muscles and has shown positive influence on respiratory mechanics ${ }^{10}$.

GPR method treat the body as a whole in an global way, in the same time grant active role to the patient, who is also a protagonist in his recovery. ${ }^{19,22}$ Nevertheless none of these techniques so far has been shown significant results. Hence the treatment still remains to be optimized and lacks the much needed standardization.

A study conducted by Marlene Aparecida Moreno et. al pointed that the GPR method given for 30 min twice a week for 8 weeks totalling 16 sessions on sedentary young males who presented with muscle shortening and altered posture showed significant improvement in pulmonary function and chest excursion ${ }^{20}$. It increases chest expansion and respiratory muscle strength in healthy young women ${ }^{24}$ The GPR may be definite a 'proprioceptive active inhibition method' that uses the "myotatic inverse reflex" to inhibit the tone in excess of the muscles of the static. In fact, by a passive method is not possible, in the short period, to win the tensions of the static muscles. ${ }^{21}$ GPR affects the muscle group in an integrated fashion, facilitating adaptation that promotes improvement in flexibility and strength. ${ }^{22,23}$ GPR method of Stretching of a muscle fiber promotes a serial increase in the number of sarcomeres. ${ }^{25,26,27}$

And further it suggested that future studies should involve individuals that present obstructive respiratory diseases, classic example of $\mathrm{COPD}^{18}$. This study was conducted to determine the effects of GPR on pulmonary functions and chest excursion in moderate COPD patients

\section{Methodology}

An experimental study with 40 patients selected by simple random sampling with treatment duration of 30 minutes for 2 sessions/ week for 2 months. Outcome measures: $\mathrm{FEV}_{1} / \mathrm{FVC}$ ratio ,Chest Expansion are measured by Electronic spirometer and inch tape

Inclusive Criteria: Age between 40-50 years male patients, GOLD criteria Stage 2: moderate COPD ,Subjects with dyspnea grade-1 according to MMRC. Subjects who are able to understand local language, Ability to provide informed consent.

Exclusive Criteria: Symptomatic Cardiovascular problems. COPD with infection Musculoskeletal disorders. Subjects not able to tolerate 30 min GPR program.

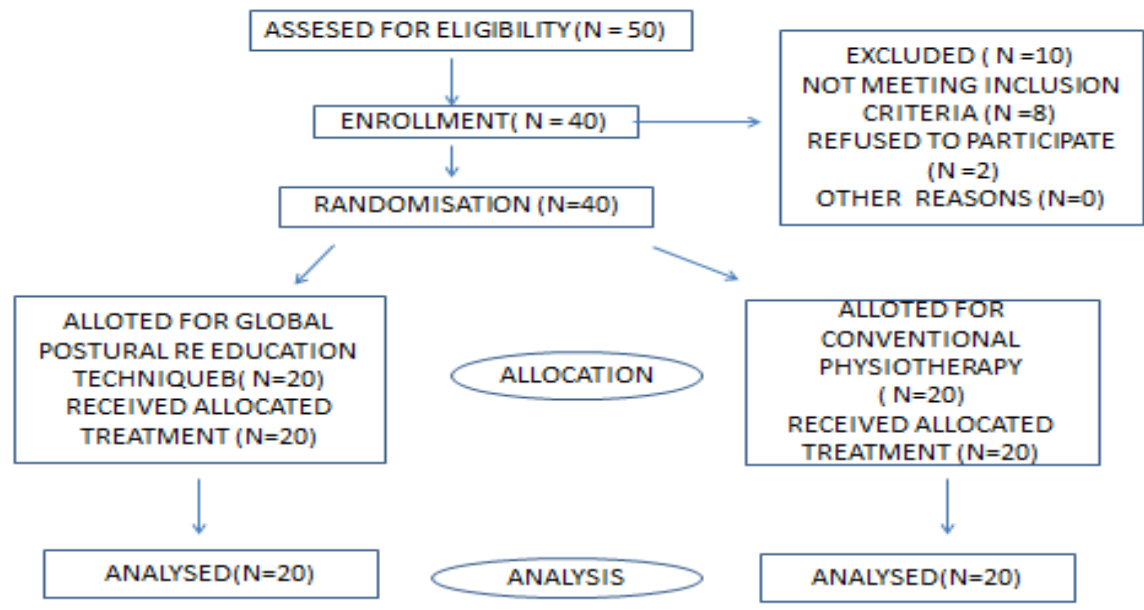

\section{Procedure}

Patients clinically diagnosed with moderate COPD were treated in outpatient basis, and expected to visit regularly 2 days per week for 8 weeks during the program. The subjects were randomly assigned in to control group and experimental group. After 16 sessions post test was done and results were analysed.

\section{Interventions}

Conventional physiotherapy:

Positioning,Apical and Lateral costal breathing,Mucus clearance techniques and Thoracic mobility exercises 


\section{Global postural re-education method:}

Respiratory muscle stretching by using GPR method in the "Open arm, Open hip joint angle" Supine position and submitted to a diaphragmatic relaxation maneuver that consists of applying gentle, sliding pressure with the finger tips, working bilaterally from the xiphicostal angle to the lower ribs. This maneuver was done to relax the diaphragm in preparation for the stretching.

The subject was then positioned with his arms at angle of approximately 45 degrees to the body, forearms downs, palms up, legs spread, hips flexed, knee bent and soles of the feet together. Pressure was applied to the back in order to align the dorsal and cervical curves of the spinal column. Whereas sacral pressure was used in order to straighten the lumbar spine.

The subject was instructed to the spread his hips from the initial position maintaining the soles of the feet together in alignment with the body axis and then verbal commands and manual contact are given in order to maintain the alignment and necessary postural corrections were made to optimizing the stretching and discouraging compensatory movements.

The subject was instructed to the inhale calmly and the exhale slowly lowering the ribcage and extending the abdomen as much as possible in order to stretch the respiratory muscles, where assistance was given to maintain the axial lengthening. During the postural exercise, the arms were kept abducted with progressive stretching of the postural muscles, thereby avoiding compensatory movements. Legs remained in apposition and advanced caudally, in order to stretch the lumbar curve, which is in contact with the surface used for support.

The same postural exercise was performed in all of the sessions in each of which, the posture was advanced to the limit for each subject promoting the progressive stretching of the muscle groups involved in the postural exercise during the treatment and this posture was maintained for 30 minutes.

\section{Outcome measures:}

1.Pulmonary Function Test: Performed using a portable electronic spirometer, to asses $\mathrm{FEV}_{1} / \mathrm{FVC}$ ratio. The test was repeated for three times until the largest value of $\mathrm{FEV}_{1} / \mathrm{FVC}$ ratio was given out automatically by spirogram.

2.Chest Excursion: Supine lying on the bed, without pillow, with arms extended along the sides of the trunk and chest uncovered. Then chest circumference was measured by using a measuring tape at 3 levels; Axillary, nipple and xiphisternal levels, The measurements were made twice at each level during the end of the maximal inspiration and expiration. The values were calculated as the difference between the inspiratory and expiratory measurement at three levels.

\section{Result}

Statistical analysis was done using the statistical GRAPH PAD software version 3.10 for this purpose the data was entered into Microsoft Excel spreadsheet, tabulated and subjected to statistical analysis. To observe the treatment impact before and after the treatment in the groups, analysis is carried out by using Paired t- test for within the groups, Unpaired t-test for between groups.

Table-1;

Analysis of CONTROL GROUP with pre and post intervention.

To compare Pre-Post intervention of parameters, the Paired t-test has been utilized. It is observed that the post intervention have shown some significant impact on subjects.

\begin{tabular}{|c|c|c|c|c|c|c|}
\hline Parameters & $\mathbf{N}$ & Mean & $\begin{array}{l}\text { Standard } \\
\text { Deviation }\end{array}$ & T-Value & D F & P-Value \\
\hline $\mathrm{Fev}_{1} / \mathrm{Fvc}$ Ratio(Pre) & 20 & 53.35 & 2.231 & \multirow{2}{*}{8.480} & \multirow{2}{*}{19} & \multirow{2}{*}{$<0.0001$} \\
\hline $\mathrm{Fev}_{1} /$ Fvc Ratio (Post) & 20 & 58.7 & 1.852 & & & \\
\hline $\begin{array}{l}\text { Chest Excursion At Axillary Level } \\
\text { (Pre) }\end{array}$ & 20 & 1 & 0.00 & \multirow[b]{2}{*}{ - } & \multirow{2}{*}{-} & \multirow{2}{*}{ - } \\
\hline $\begin{array}{l}\text { Chest Excurion At Axillary Level } \\
\text { (Post) }\end{array}$ & 20 & 1 & 0.00 & & & \\
\hline $\begin{array}{l}\text { Chest Excursion At Nipple Level } \\
\text { (Pre) }\end{array}$ & 20 & 1.25 & 0.4443 & \multirow[t]{2}{*}{2.517} & \multirow[t]{2}{*}{19} & \multirow[t]{2}{*}{$<0.0110$} \\
\hline $\begin{array}{l}\text { Chest Excursion At Nipple Level } \\
\text { (Post) }\end{array}$ & 20 & 1.5 & 0.5130 & & & \\
\hline $\begin{array}{l}\text { Chest Excursion At Xiphi Sternum } \\
\text { (Pre) }\end{array}$ & 20 & 1.15 & 0.3663 & \multirow[t]{2}{*}{2.854} & \multirow[t]{2}{*}{19} & \multirow[t]{2}{*}{$<0.0102$} \\
\hline $\begin{array}{l}\text { Chest Excurion At Xiphi Sternum } \\
\text { (Post) }\end{array}$ & 20 & 1.45 & 0.5104 & & & \\
\hline
\end{tabular}


Comparison of mean scores of pre and post $\mathrm{FEV}_{1} / \mathrm{FVC}$ ratios of CONTROL group

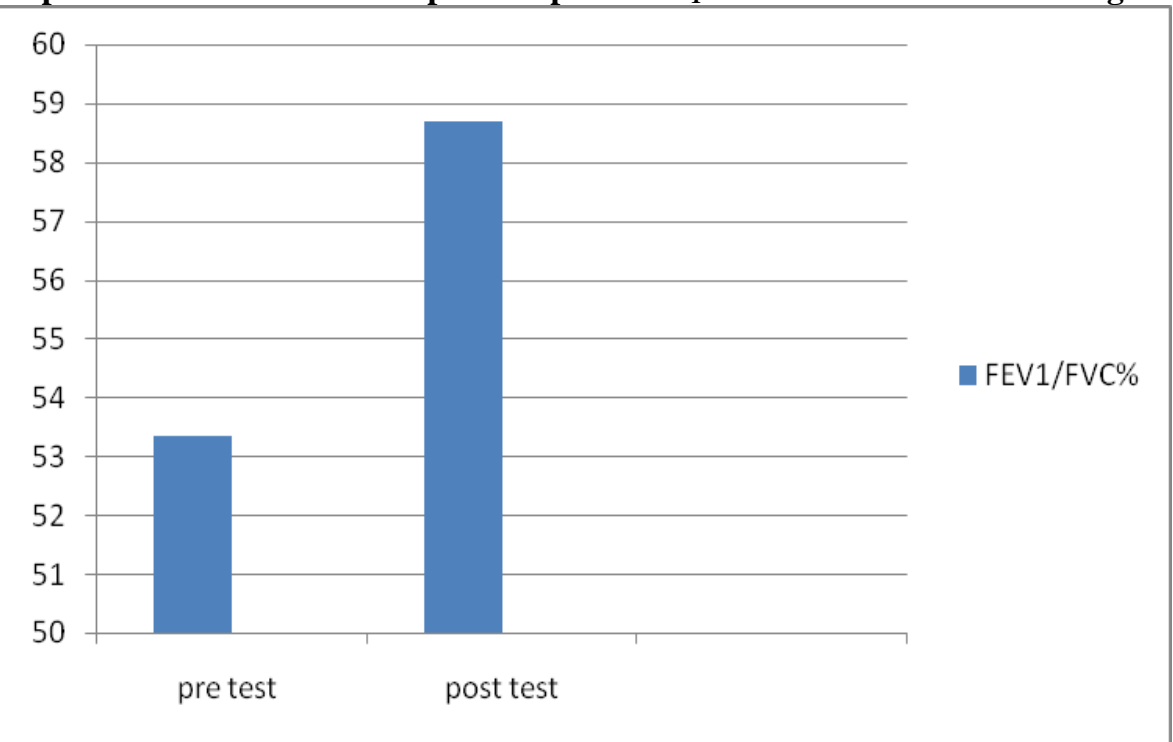

Comparison of mean scores of pre \& post Chest Excursion of CONTROL group

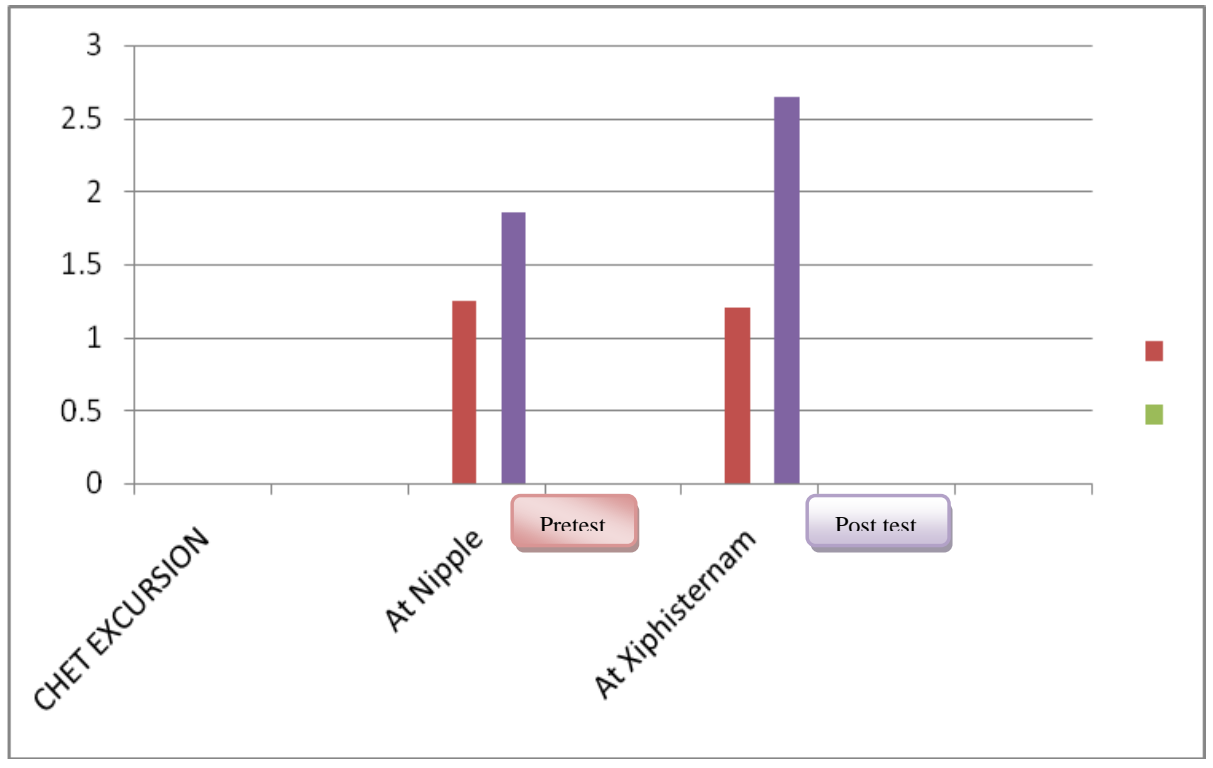

Table-2; Analysis Of Experimental Group With Pre \& Post Intervention:

\begin{tabular}{|c|c|c|c|c|c|c|}
\hline Parameters & $\mathbf{N}$ & Mean & $\begin{array}{l}\text { Standard } \\
\text { Deviation }\end{array}$ & T-Value & D F & P-Value \\
\hline $\mathrm{Fev}_{1} / \mathrm{Fvc} \mathrm{Ratio}$ (Pre) & 20 & 52.7 & 1.658 & \multirow{2}{*}{79.096} & \multirow{2}{*}{19} & \multirow{2}{*}{$<0.0001$} \\
\hline $\mathrm{Fev}_{1} /$ Fvc Ratio (Post) & 20 & 76.55 & 2.259 & & & \\
\hline $\begin{array}{l}\text { Chest Excursion At Axillary Level } \\
\text { (Pre) }\end{array}$ & 20 & 1 & 0.00 & \multirow[b]{2}{*}{-} & \multirow[b]{2}{*}{-} & \multirow[b]{2}{*}{-} \\
\hline $\begin{array}{l}\text { Chest Excurion At Axillary Level } \\
\text { (Post) }\end{array}$ & 20 & 1 & 0.00 & & & \\
\hline $\begin{array}{l}\text { Chest Excursion At Nipple Level } \\
\text { (Pre) }\end{array}$ & 20 & 1.25 & 0.4443 & \multirow{2}{*}{5.339} & \multirow[t]{2}{*}{19} & \multirow[t]{2}{*}{$<0.0001$} \\
\hline $\begin{array}{l}\text { Chest Excursion At Nipple Level } \\
\text { (Post) }\end{array}$ & 20 & 1.85 & 0.3663 & & & \\
\hline $\begin{array}{l}\text { Chest Excursion At Xiphi Sternum } \\
\text { (Pre) }\end{array}$ & 20 & 1.2 & 0.4104 & \multirow[t]{2}{*}{12.704} & \multirow[t]{2}{*}{19} & \multirow[t]{2}{*}{$<0.0001$} \\
\hline $\begin{array}{l}\text { Chest Excurion At Xiphi Sternum } \\
\text { (Post) }\end{array}$ & 20 & 2.65 & 0.4894 & & & \\
\hline
\end{tabular}


Comparison of mean scores of pre and post $\mathrm{FEV}_{1} / \mathrm{FVC}$ ratio of EXPERIMENTAL group.

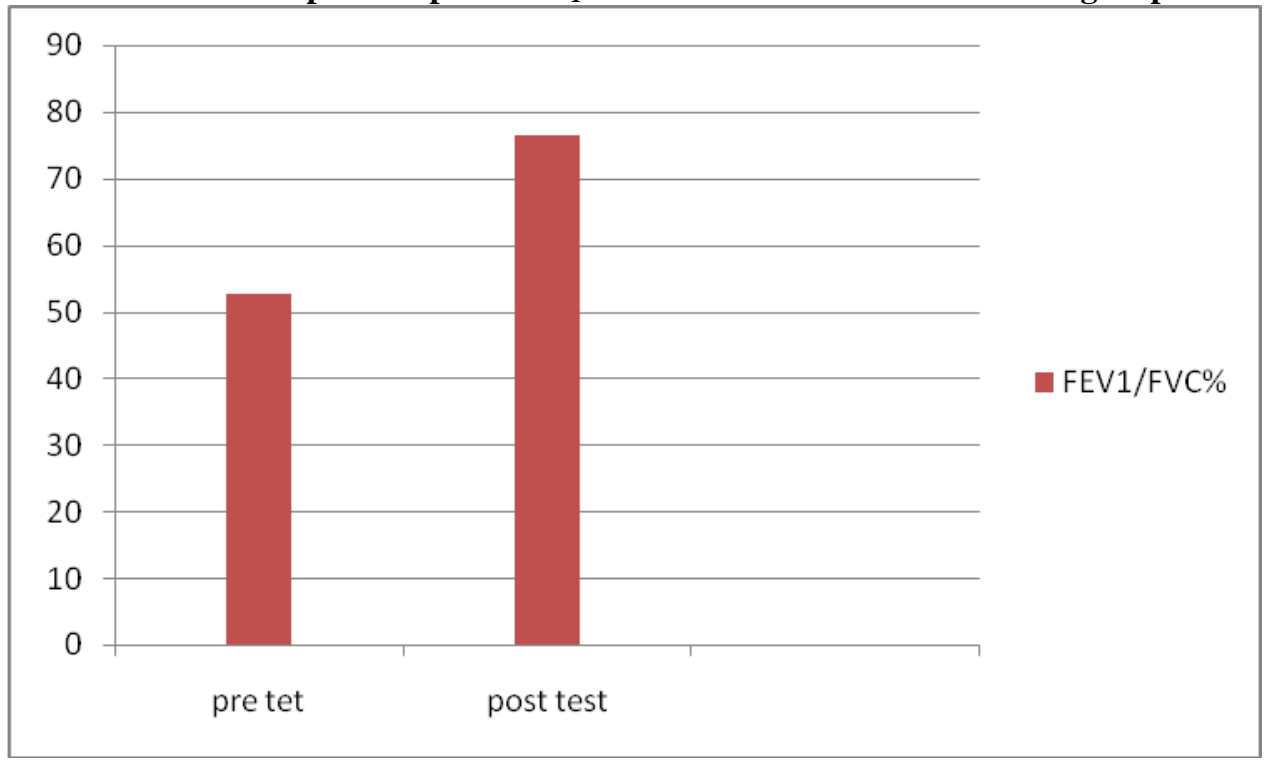

Comparion of mean scores of pre \& post Chest Excursion of EXPERIMENTAL group.

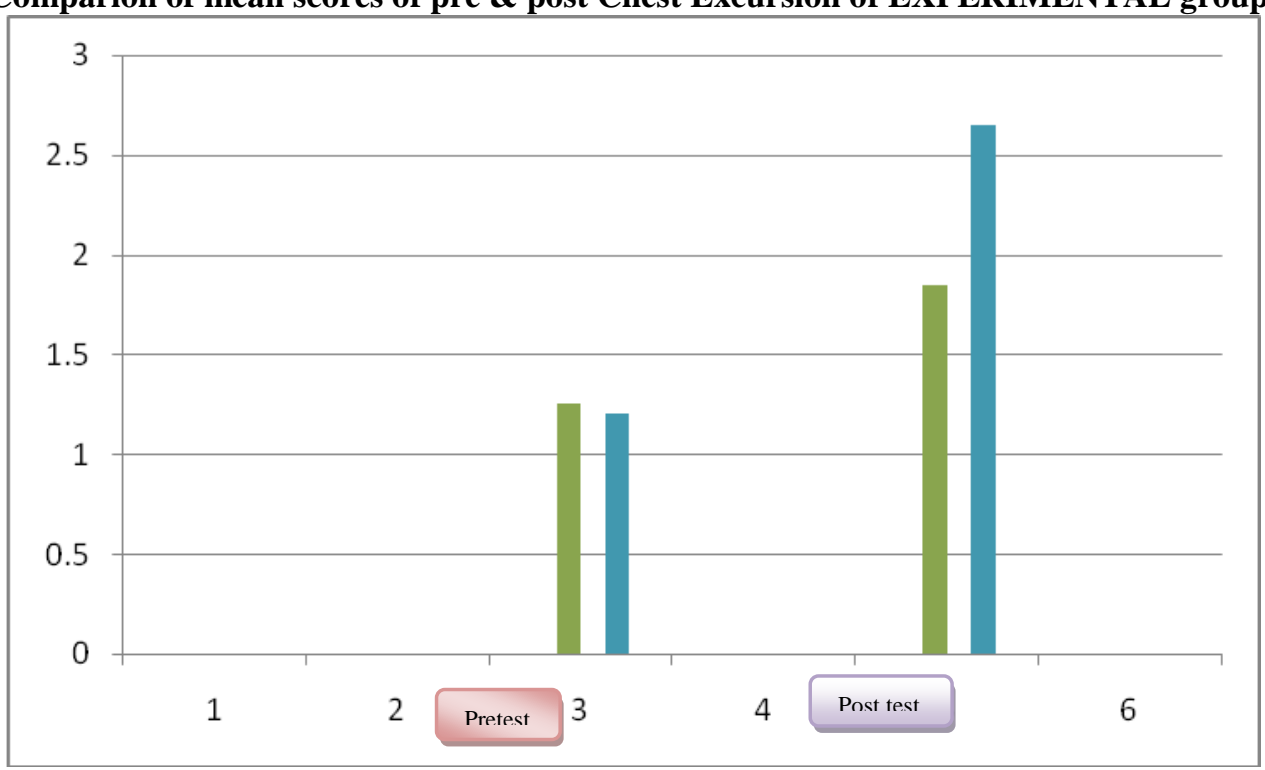

Table-3 ; Analysis Of Effectiveness Of The Treatment Among Two Groups Of The Parameters.

\begin{tabular}{|c|c|c|c|c|c|c|}
\hline Parameters & $\mathbf{N}$ & Mean & $\begin{array}{l}\text { Standard } \\
\text { Deviation }\end{array}$ & T-Value & D F & P-Value \\
\hline Con.Fev $_{1} /$ Fvc Ratio(Post) & 20 & 58.7 & 1.852 & \multirow{2}{*}{27.410} & \multirow{2}{*}{38} & \multirow{2}{*}{$<0.0001$} \\
\hline Exp.Fev $_{1} /$ Fvc Ratio (Post) & 20 & 76.55 & 2.259 & & & \\
\hline $\begin{array}{l}\text { Con. Chest Excursion At Axillary } \\
\text { Level (Post) }\end{array}$ & 20 & 1 & 0.00 & \multirow[b]{2}{*}{ - } & \multirow[b]{2}{*}{-} & \multirow[b]{2}{*}{ - } \\
\hline $\begin{array}{l}\text { Exp. Chest Excursion At Axillary } \\
\text { Level (Post) }\end{array}$ & 20 & 1 & 0.00 & & & \\
\hline $\begin{array}{l}\text { Con. Chest Excursion At Nipple } \\
\text { Level (Post) }\end{array}$ & 20 & 1.5 & 0.5130 & \multirow{2}{*}{2.483} & \multirow[t]{2}{*}{38} & \multirow[t]{2}{*}{$<0.0001$} \\
\hline $\begin{array}{l}\text { Exp. Chest Excursion At Nipple } \\
\text { Level (Post) }\end{array}$ & 20 & 1.85 & 0.3663 & & & \\
\hline $\begin{array}{l}\text { Con. Chest Excursion At Xiphi } \\
\text { Sternum (Pot) }\end{array}$ & 20 & 1.45 & 0.5104 & \multirow[t]{2}{*}{7.589} & \multirow[t]{2}{*}{38} & \multirow[t]{2}{*}{$<0.0001$} \\
\hline $\begin{array}{l}\text { Exp. Chest Excurion At Xiphi } \\
\text { Sternum (Post) }\end{array}$ & 20 & 2.65 & 0.4894 & & & \\
\hline
\end{tabular}


On observing the means of post test parameters of CONTROL and EXPERIMENTAL groups, Independent $\mathrm{t}$-test was done and the P-value is $<0.05$.It hows a significant difference BETWEEN the two groups.

Comparison of Post FEV $1 /$ FVC ratio means between two groups.

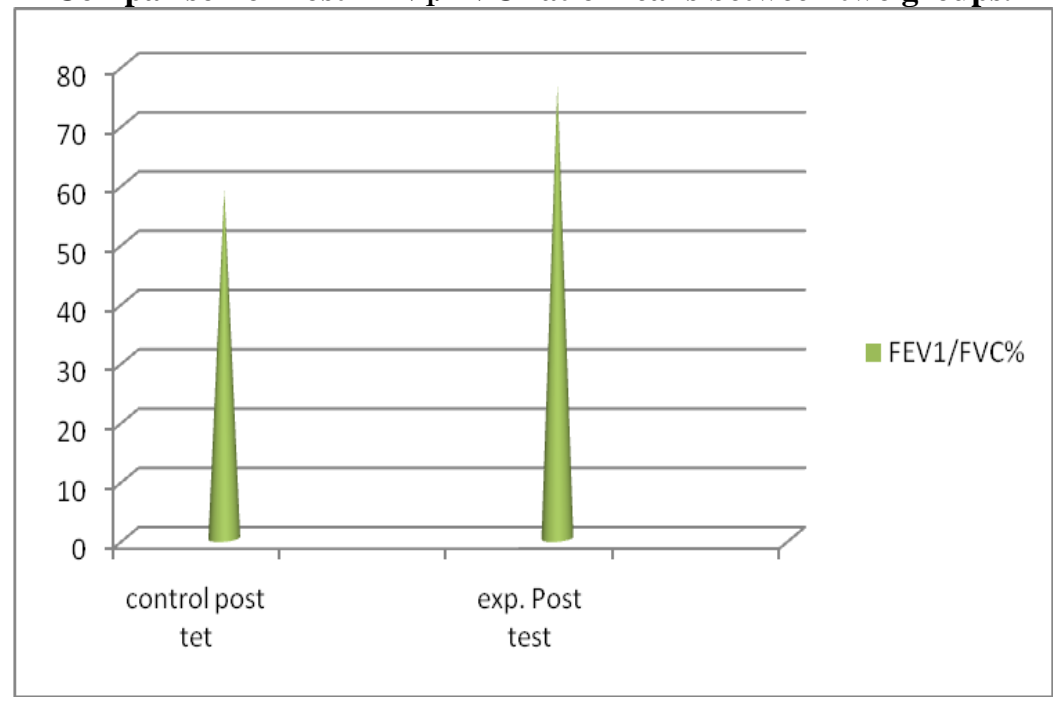

Comparison of Post Chest Excursion means between two group.

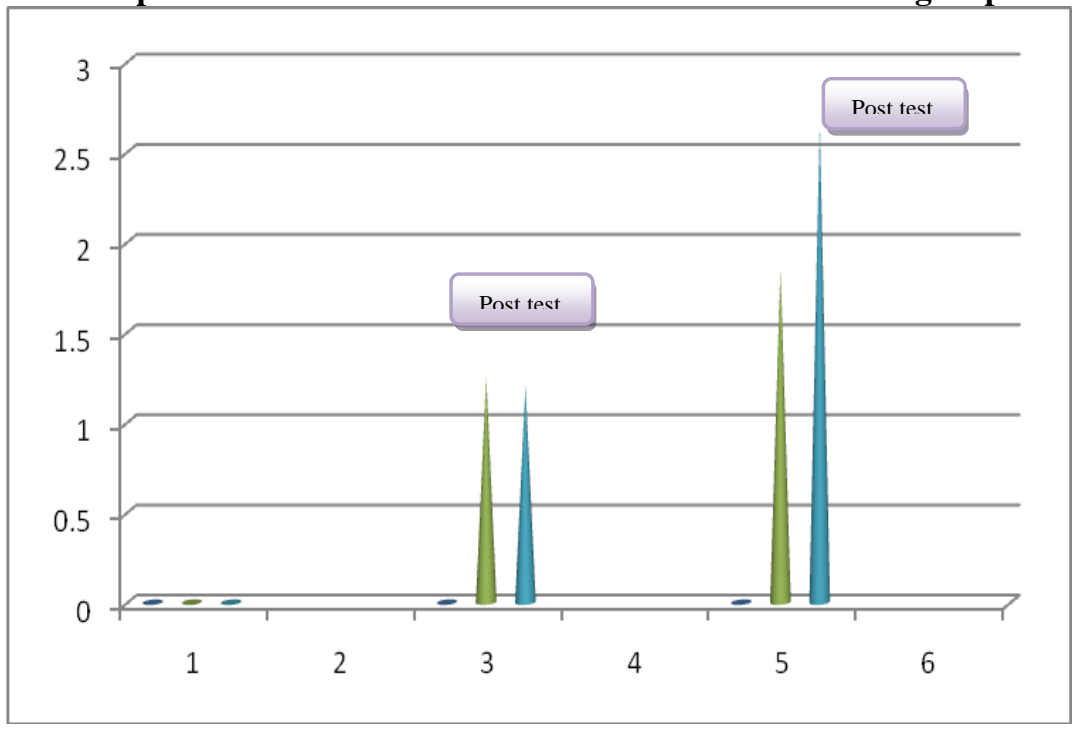

Overall results of the present study were analyzed which shows a ignificant improvement in experimental group when compared to control group in $\mathrm{FEV}_{1 / 1} \mathrm{FVC}$ ratio and Chest Excursion.

\section{Discussion}

The results of the study has shown substantial improvement in pulmonary function and chest excursion in GPR group than the subjects in the control group, where routine conventional physiotherapy only is followed.Whereas the GPR group involved in respiratory muscle stretching program with 'open-arm, open hip joint angle' posture performed twice a week for a period of 8 weeks along with conventional physiotherapy.

In Conventional group FEV1/FVC pre -posttest values are $p<0.0001$ which shows statistically significant improvement and chest percussion measurement values were $\mathrm{p}<0.0210$ and $\mathrm{p}<0.01102$ which proves that improvement in nipple level and xiphisternal levels were not significant. In Experimental group the FEV1/FV pre-post test values are $\mathrm{p}<0.0001$ which shows statistially significant improvement and chest percussion measurement values were $p<0.001$ and $p<0.0001$ which proves the improvement in nipple level and xiphisternal levels were much statistically significant. Comparing Control and Experimental group the FEV1/FVC values were $<0.0001$ which shows statistically significant improvement and chest percussion measurement values were $\mathrm{p}<0.0001$ and $\mathrm{p}<0.0001$ which proves the improvement in nipple and xiphisternal levels were much statistically significant 
Several previous literature of Global Postural Re-education method has advocated that the pulmonary function and chest excursion of GPR group is improved because of the increase in the number of sarcomeres in series promoted by lengthening, improving the interaction between actin and myosin contractile capacity and increasing the length of respiratory muscles and also improving the length -tension relationship of the respiratory muscle fibers. However, the open-arm, open hip joint angle posture allow greater stability for the diaphragmatic insertions which is ideal for stretching the muscles like diaphragm, the sternocleidomastoid muscle and dorsal muscles, as well as major and minor pectoral muscles. There were no studies till date on GPR method for COPD therefore this study taken on COPD subjects in whom, treatment needs are essential and the results of present study shows that the 'open-arm, open hip joint angle' posture in the GPR method is efficient in promoting an increase in the pulmonary function and greater chest excursion in COPD subjects.

\section{Conclusion}

Thus the above study concludes that GPR had significant statistical improvement on pulmonary functions and chest excursion in moderate COPD patients. Thus this study accepts alternate hypothesis

\section{Limitations :}

The sample size was small The study was short term Frequency of treatment sessions is less.

\section{Recommendations:}

Application of GPR in female COPD subjects. Studies on this approach in other respiratory conditions by changing posture in GPR method. Can compare GPR method to other respiratory physiotherapy approaches.

\section{Conflicts of interest:}

\section{Nil}

Source of funding :

Krishna institute of medical sciences deemed university, karad.

Ethical clearance:

study approved by institutional ethics comitee of Krishna institute of medical sciences,karad.

\section{Bibliography}

[1]. Global strategy for the diagnosis, management, and prevention of chronic obstructive pulmonary disease.(GOLD,2006).

[2]. Datamonitor ; Epidemiology: COPD in India. April 1,2015.

[3]. SK Jindal COPD; The unrecognized epidemic in india.feb 2012.vol.60.

[4]. Rob CI Wijst, Hans Degens ; Factors contributing to muscle wasting and dysfunction in COPD patients.2007:2(3) 289-300.

[5]. R.J. Halbert, MD, MPH; Sharon Isonaka, MD, MS; Dorothy George, Pharam D; Interpreting COPD prevalence Estimates, what is the true burden of diseae. CHEST /123/5 May,2003.

[6]. B.R.Celli, W.MacNee. and committee members ; Standards for the diagnosis and treatment of patients with COPD; a summary of the ATS/ERS Position paper, Eur Respir J2004;932-946.

[7]. C.A.C.Ottenheijm, G.J.Jenniskens, M.C.P.Geraedts; Diagram dysfunction pulmonary disease: a role for heparan sulphate?Eur respir J 2007;30:80-89.

[8]. Harry R Gosker, Emiel FM Wouters, Ger J van der Vusse ; Skeletal muscle function in chronic obstructive pulmonary disease and chronic heart failure ; underlying mechanisms and therapy perspectives. Am J Clin Nutr 2000;71;1033-47.

[9]. M.Orozco-Levi ; Structure and function of the respiratory muscles in patients with COPD: impairment or adaption? Eur Respir J 2003; 22:suppl. 46,41s-51s.

[10]. Patrica A.Downie : Chest, heart and vascular disorder for physiotherapists, page no: 498

[11]. Jenifer A Pryor ; Physiotherapy for cardiac and vascular problems page no: 560

[12]. Alberta-college + Association; Facts about Physiotherapy's role in COPD treatment and management 1.800.291.2782 September 2011.

[13]. Franco laghi and Martin j. tobin; Disorders of the respiratory muscles and respiration in critical care med vol 168. pp 10-48, 2003.

[14]. Philippe e. souchard; What is re education of postural muscles ?

[15]. Philippe e. souchard; Global postural re-education.

[16]. Marlane aparecida moreno, Aparecida maria catai, Rosana macher teodori; Effect of a muscle stretching program using the global postural Re education method on respiratory muscle strength and thoracoabdominal mobility of sedentary young males.

[17]. HR. Gosker et al, ; Myopathological features in skeletal muscle of patients with COPD. Eur Respir j 2003; 22 : $280-285$.

[18]. Sameer B.Shah, david peters, kimberly a. jordan, Derek j.milner; Sarcomere number regulation maintained after immobilization in Desmin-null Mouse Skeletal muscle.23 April 2001.

[19]. Thomas j. Brukholder and Richard 1. lieber; Sarcomere length Operation Range of Vertebrate Muscles During Movement .5 April 2001.

[20]. E.l.coutinho, A.R.S.Gomes, C.N.Franca, J. Oishi; Effect of possive stretching on the immobolized muscle fiber morphology. Braz J Med Biol Res 37(12) 2004.

[21]. Eitaro kubo, Hiroaki kanehisa, Yasuo kawakami; Influence of static stretching on viscoelastic properties of human tendon structures in vivo.

[22]. P.e. williams and g. Goldspink; Changes in sarcomere length and physiological properties in immobilized muscle. J. Anat. (1978) 127, 3,pp 459-468, 
[23]. Michael T. Putt, MBBS, Michelle Watson, BPhty, Helen Sealse, Jennifer D. Paratz, Phd; Muscle Stretching Technique Increases Vital Capacity and Range of Motion in patients with Chronic Obstructive Pulmonary Disease. Arch Phys Med Rehabil Vol 89, June 2008.

[24]. Adaptions of the respiratory system related to lung function in response to a program of muscle stretching method of Global Postural Re-education. Vol 220, No 8. Feb 2012

[25]. Kaku yoshimi, Jun ueki, kuniaki seyama, Makiko takizawa, Seiko yamaguchi., Eriko kitahara; Pulmonary rehabilitation program including respiratory conditioning for chronic obstructive pulmonary disease ( COPD); Improved hyperinflation and expiratory flow during tidal breathing. ISSN: 2072-1439.

[26]. Rosana m.teodori, julia r. Negri, monical c. Cruz, Amelia p. marques ; Global Postural Re-education a literature review. Rev Bars Fisioter. 2011;15(3): 185-9.

[27]. Marilyn $\quad$ r. Gossman, Shirley a. Sahrmann, and steven j. rose ; Review of length - associated changes in muscle. jan 18,2013.

[28]. Richard debigare, Claude h. cote, and Fracis Maltais; Peripheral muscular wasting in chronic obstructive disease. In respiratory care med vol 164.pp 1712-1717, 2001. 